\title{
Finite Element Analysis to determine the optimum contact pressure between the components of a hip implant made by using the Selective Laser Sintering and the Selective Laser Melting Technologies
}

\author{
Răzvan Păcurar ${ }^{1, *}$, Ancuţa Păcurar $^{1}$, and Anna Petrilak $^{1}$ \\ ${ }^{1}$ Technical University of Cluj-Napoca, Faculty of Machine Building, Department of Manufacturing \\ Engineering, B-dul Muncii no. 103-105, 400641, Cluj-Napoca, Romania
}

\begin{abstract}
The article presents a case study that was realized at the Technical University of Cluj-Napoca (TUC-N) in the field of customized medical implants made by using different additive manufacturing (AM) technologies, such as the Selective Laser Sintering (SLS) and the Selective Laser Melting (SLM). Finite element analysis was successfully used to determine the mechanical behavior of an acetabular liner that was made from PA 2200 powder material by SLS and to determine the optimum technological parameters required to be used in the manufacturing process of the acetabular liner by SLS, so as the contact pressure between the acetabular liner made from PA 2200 material by SLS and the femoral head made from TiAl6V4 material by SLM will be optimum at the end and the displacement between the components will remain in the admissible limits.
\end{abstract}

\section{Introduction}

Selective Laser Sintering (SLS) and Selective Laser Melting (SLM) technologies are two of the most developed Additive Manufacturing (AM) technologies which nowadays are widely used for producing medical implants (e.g. hip implants) [1,2]. Total knee and hip replacement arthroplasty are commonly used procedures in which the knee or hip joint is replaced by an artificial joint [3]. The success of the engineered artificial joint depends on the biomechanical and material properties [4-6]. A total hip replacement is shown in Fig. 1 and is composed of an acetabular component, which usually is made of metal (titanium alloys etc), a Plastic Liner (made of polymers), a femoral head and a femoral stem that are usually made of the same material as the acetabular cup [7]. One of the most important challenges regarding AM technologies is to know how to control the process parameters to obtain the adequate characteristics of a part from mechanical, thermal and biomedical point of view $[8,9]$. The orientation of the parts during the manufacturing process has also a high influence on the accuracy and characteristics of the realized medical implants, as well [10].

${ }^{*}$ Corresponding author: razvan.pacurar@tcm.utcluj.ro 


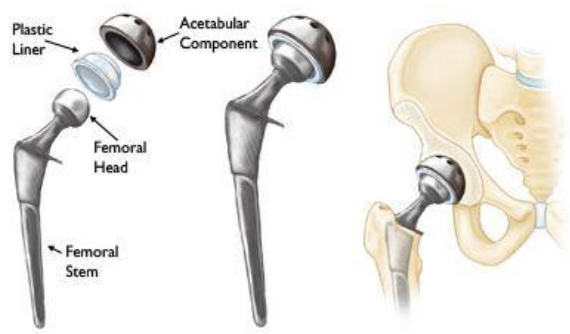

Fig. 1. The individual components of a total hip replacement [7].

Finite element analyses were performed using dedicated FEA software programs, such as ABAQUS, ANSYS, etc. to simulate the positioning between the femoral head and polyethylene liner, which is shown in Fig. 1. All the material were modeled as homogenous, isotropic âand linear elastic, excepting the plastic liner which was considered as being a non-linear elasto-plastic [11]. The contact areas on the articulating surface were located about the superior region of the liner. The conclusion of the made analyses was that in the case of a microseparation equal with $2000 \mu \mathrm{m}$, the contact pressure is centralized at the rim of the liner, leading to a high contact area at the rim liner and elevated stress which can cause severe plastic deformation of the liner. The microseparation distance and the angle and positioning orientation during the manufacturing process on the machines have a significant influence on the von Misse stress and contact pressure that results at the end [12]. This paper presents results that were obtained at the Technical University of ClujNapoca (TUC-N) related to the Finite element analysis that was made in the case of a total hip replacement by using Solidworks Simulation FEA program in order to determine the stresses and contact pressure that occur in the case of an acetabular liner made of PA 2200 material by SLS and an acetabular cup made of TiAl6V4 material by SLM, components that were manufactured at the end at TUCN using dedicated AM equipment.

\section{Steps of the Finite Element Analysis}

The contact pressure analysis of total hip replacements was realized using the 3D models that were designed by using the SOLIDWORKS program as presented in Fig. 2. The dimensions of the Ti6AlV4 alloyed acetabular cup that was made at TUCN by SLM were measured and transposed to the 3D model. The outside diameter of the acetabular cup (marked with 1 in Fig. 2) was $56 \mathrm{~mm}$, the inside diameter being $46 \mathrm{~mm}$. The acetabular liner dimension (marked with 2 in Fig.2) made from PA 2200 material by SLS and the femoral head (marked with 3 in Fig. 2) made from TiAl6V4 by SLM were chosen according to the specifications of the Waldermark Link Company from Germany [13]. The plastic acetabular liner has been designed in consequence having the outside diameter of 46 $\mathrm{mm}$, the inside diameter being designed as having a dimension of $32 \mathrm{~mm}$. The femoral cup is a $31 \mathrm{~mm}$ spherical component. In order to simplify the FEA model, the 3D models have been designed as simple hemispheres as shown in Fig. 2 (without lattice structures on the surfaces of the acetabular cup and without reinforcement on the acetabular liner outer surface. In order to determine the mechanical behavior of the acetabular liner made of PA 2200 material, a static study was performed using SOLIDWORKS Simulation program.

After the character of the study was defined, the materials of the individual components were set, with Linear Elastic Isotropic characteristics, specifying as following: for both, the acetabular cup and femoral head made by SLM from Ti6Al4V material, the mechanical and thermal characteristics (e.g. Young Elastic modulus E=104 GPa, the coefficient of Poisson $\xi=0.31$ ) were selected as they were found within SOLIDWORKS Simulation library. 

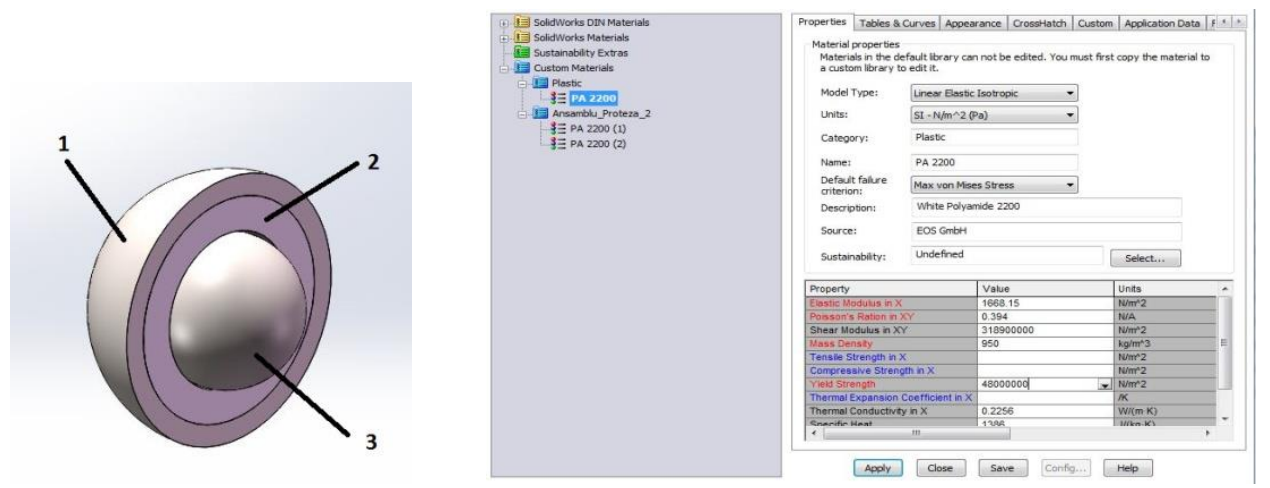

Fig. 2. FEA model of hip replacement. Definition of PA2200 characteristics in SolidWorks.

Further on, due to the fact that the type of material the plastic liner is made from (PA 2200) was not found within the Solidworks Material Library feature, the definition of a new type of material was required to be realized, with the mechanical and thermal characteristics determined based on experimental tests that were made at TUCN by using different samples, required for tensile or compressive test experiments (see Fig.2).

The next step in FEA analyses was the definition of the boundary and displacement constrains (see Fig.3).
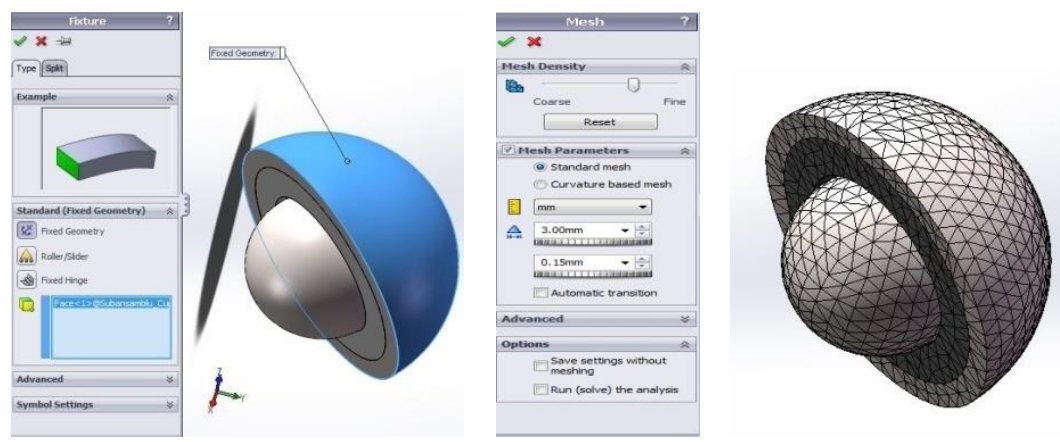

Fig. 3. Boundary and displacement constrains imposed within the FEA analysis. Mesh characteristics.

First, the Component Contact Type was set as Global Contact with No Penetration between the femoral head, the acetabular liner and the cup subassembly and with a friction coefficient equal to $0.6 \mu \mathrm{m}$ according to the values found in other research that was made regarding the contact pressure values between the hip replacement components [14]. From the designing stage a boundary condition was given to the acetabular cup and liner assembly, allowing a rotation of 20 degree around $x$ axis (anteversion of the cup) and 45 degree around y axis (cup abduction). The main boundary condition was given as fixture of the acetabular cup as shown in fig.3 in order to keep fixed the model in the same position as it was defined by the inclination in the $3 \mathrm{D}$ designing stage of the models. The application of boundary conditions in this way for the realized biomechanical Finite Element Analysis was based on assumptions including forces and pressures acting in the human body as well as displacements and symmetry boundary conditions based on simplifications in the model.

Within this analysis an external load was applied as displacement of the femoral head equal with $0.1 \mathrm{~m}$. Several other research that were made demonstrated that a possible displacement between the acetabular cup and femoral head is between 0.03 and $0.35 \mathrm{~mm}$ (depending on the bone structure the implant is implanted in and the age of the patient) 
[11]. The next step required to be realized before running the FEA analysis was the mesh generating procedure which was performed as shown in fig.3. The mesh parameter (standard type) was selected so as $3 \mathrm{~mm}$ dimension were set for the tetrahedral elements.

\section{Results of the Finite Element Analysis}

After following all the steps of the analysis, as decribed above, it was possible to run the analysis to determine the displacement, stress and contact pressure between the components (see fig. 4).
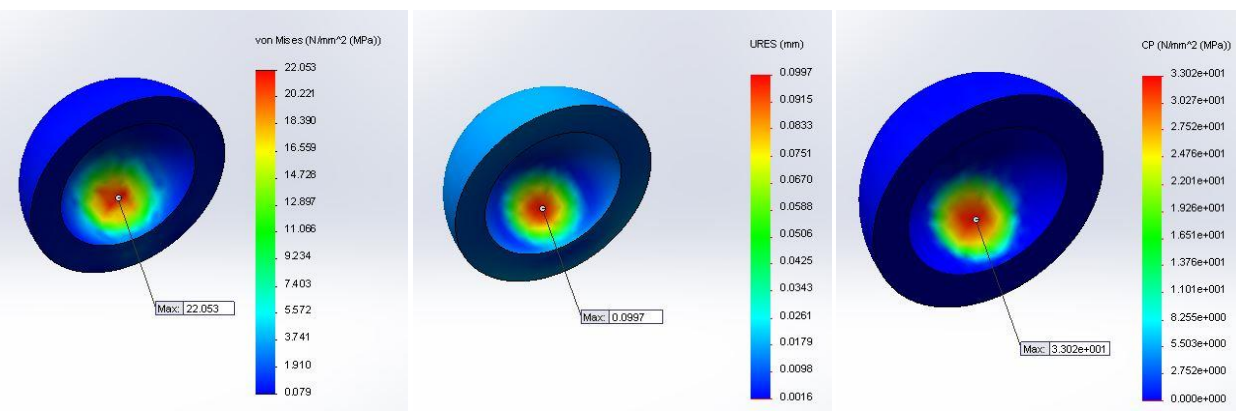

Fig. 4. Distribution of the von Mises stress, displacement and contact pressure between components.

The finite element analysis was performed by taking into consideration different values of the mechanical characteristics (the average values of the Young modulus E, the compression limit strength $\mathrm{Rdx}$ and the mechanical resistance at the failure $\mathrm{Rm}$ ), as these characteristics were determined in the case of different batches of samples that were made from PA 2200 powder by Selective Laser Sintering (SLS), using different settings of laser power (LP) and orientation in the working chamber of the SLS machine (see Fig. 5 and Table 1).

Table 1. Technological parameters, compression test values and finite element results for different settings of PA2200 material characteristics.

\begin{tabular}{|c|c|c|c|c|c|c|c|}
\hline $\begin{array}{c}\text { PA2200 } \\
\text { Samples }\end{array}$ & $\begin{array}{c}\mathbf{L P} \\
{[\mathbf{W}]}\end{array}$ & $\begin{array}{c}\text { Orientation } \\
\left({ }^{\circ}\right)\end{array}$ & $\begin{array}{c}\mathbf{E} \\
{\left[\mathbf{N} / \mathbf{m m}^{2}\right]}\end{array}$ & $\begin{array}{c}\mathbf{R d x} \\
{\left[\mathbf{N} / \mathbf{m m}^{2}\right]}\end{array}$ & $\begin{array}{c}\mathbf{R m} \\
{\left[\mathbf{N} / \mathbf{m m}^{2}\right]}\end{array}$ & $\begin{array}{c}\boldsymbol{\sigma m a x} \\
{[\mathbf{N} / \mathbf{m m} 2]}\end{array}$ & $\begin{array}{c}\mathbf{C p} \\
{[\mathbf{N} / \mathbf{m m} 2]}\end{array}$ \\
\hline I (1-5) & 4.5 & $\mathrm{y}=0^{\circ}$ & $1,413,735$ & 33,33 & 99,08 & 22.53 & 33.02 \\
\hline II (11-15) & 4.5 & $\mathrm{y}=90^{\circ}$ & $1,174,300$ & 32,95 & 90,48 & 18.33 & 27.45 \\
\hline III (21-25) & 4 & $\mathrm{y}=0^{\circ}$ & 678,487 & 15,23 & 40,34 & 10.6 & 15.88 \\
\hline IV (31-35) & 4 & $\mathrm{y}=90^{\circ}$ & 591,062 & 12,08 & 31,51 & 9.24 & 13.84 \\
\hline V (41-45) & 4.5 & $\mathrm{z}=-45^{\circ}$ & 419,724 & 10,63 & 37,41 & 6.57 & 9.83 \\
\hline VI (46-50) & 4.5 & $\mathrm{z}=+45^{\circ}$ & 452,354 & 10,81 & 40,39 & 7.08 & 10.59 \\
\hline
\end{tabular}

The maximum value of the von Mises stress was obtained in the case of first set of samples made by SLS (batch I) as shown in Fig. 4 (the value of $\sigma_{\max }$ was $22.053 \mathrm{MPa}$ in this case). 

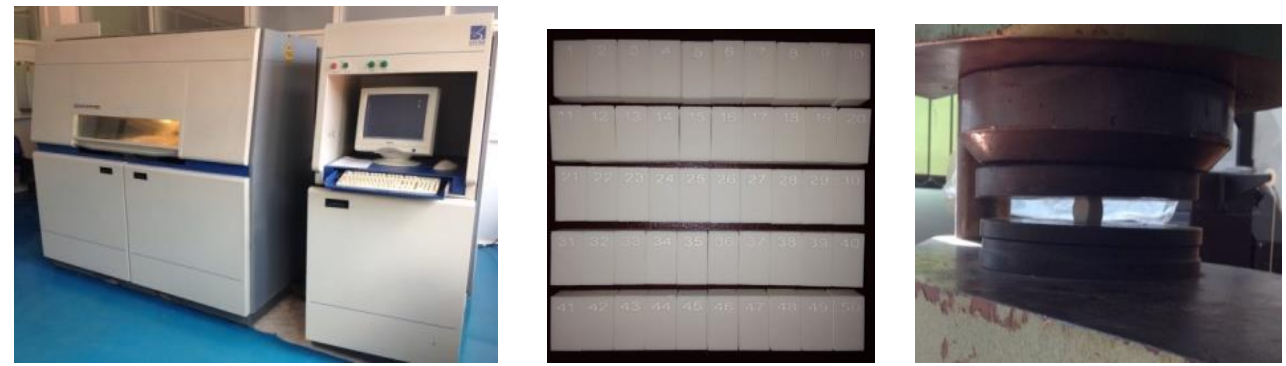

Fig. 5. DTM Sinterstation 2000 equipment, samples and compressive tests performed using the ZD 40 Tension-Compressive Testing Machine from TUCN.

One of the most important condition for a part to resist is to respect the relations:

$$
\begin{gathered}
\sigma_{\text {max }} \leq \sigma_{a} \\
\sigma_{a}=\frac{R d x}{c}
\end{gathered}
$$

in which: $\sigma_{\max }$ is the maximum von Misses stress obtained by the FEA $\left[\mathrm{N} / \mathrm{mm}^{2}\right], \sigma_{a}$ is the admissible stress $\left[\mathrm{N} / \mathrm{mm}^{2}\right], \operatorname{Rdx}$ is the compression limit strength $\left[\mathrm{N} / \mathrm{mm}^{2}\right]$ and $\mathrm{c}$ is the safety coefficient $(\mathrm{c}=1.5)$. As it was possible to notice from the results obtained as presented in table 1, in the case of batch I and II, condition (1) was respected (22,53 MPa $\leq$ $24.22 \mathrm{MPa}$ and 18.33 $\mathrm{MPa} \leq 24.22 \mathrm{MPa}$ ).In the case of samples manufactured with a laser power equal to $4 \mathrm{~W}$ under the same loading condition the relation (1) and with a laser power equal to $4.5 \mathrm{~W}$ oriented as compared to the Z-axis at $\pm 45^{\circ}$ this condition has not been respected, so in these cases it was concluded that the manufactured parts will not resist.

As regarding the displacement distribution, the maximum value which was obtained in the case of made analyses was $0.0977 \mathrm{~mm}$ as shown in Fig. 4 . The obtained value is in the admissible range of displacement between the acetabular cup and femoral head $(0.03$ and $0.35 \mathrm{~mm}$ ), values that are acceptable and reported by the researchers in this field [11]. Last but not least, regarding the contact pressure $(\mathrm{Cp})$ that has been obtained after the made analyses (see Fig.4), it is important to state the fact that the results $(\mathrm{Cp}=9.83-33.02 \mathrm{MPa})$ are comparable with those that were obtained by other researchers that have determined the contact pressure between the acetabular cup made from TiAl6V4 material and the acetabular liner made by polyethylene materials with different dimensions (36 $\mathrm{mm}$ and 40 $\mathrm{mm}$ ). The contact pressure values that was determined by this group of researchers have varied as reported between 8.2 to $60.4 \mathrm{MPa}$, in concordance with the part orientation and technological parameters that was used on the SLS machine [14]. The contact pressure value is influenced not only by the technological parameters and part orientation point of view, but also by the Young modulus, which is variable in concordance with the age of the patient and the bone characteristics (bone quality, coefficient of friction, acetabular cup acetabular liner - femoral implant - bone interaction, etc). Based on the results obtained after the finite element analyses regarding the values of the von Mises maximum stress and the contact pressure between the realized components, it was decided that the acetabular liner will be made from PA2200 material by SLS with a laser power of $4.5 \mathrm{~W}$ and an orientation of $0^{\circ}$ along the $\mathrm{Y}$-axis. 


\section{Conclusions}

Taking into consideration the results obtained regarding the mechanical characteristics of the PA 2200 samples that were manufactured by selective laser sintering (SLS) technology at the Technical University of Cluj-Napoca (TUCN) and considering the obtained results of the finite element analyses that were made for estimating the maximum stress and contact pressure between the implant components, it was decided to manufacture the acetabular liner presented in Fig. 6 with a laser power of $4.5 \mathrm{~W}$ and an orientation of $0^{\circ}$ along Y-axis, at the end. The maximum von Misses stress obtained in this case $(22,53 \mathrm{MPa})$ was in the admissible limits, as well as the contact pressure $(33.02 \mathrm{MPa})$, which was in the reported limits that were determined and presented by other researchers that have analyzed the variation of the contact pressure of the acetabular liner made from PA 2200 material by SLS, with different part orientations and different settings of the technological parameters.
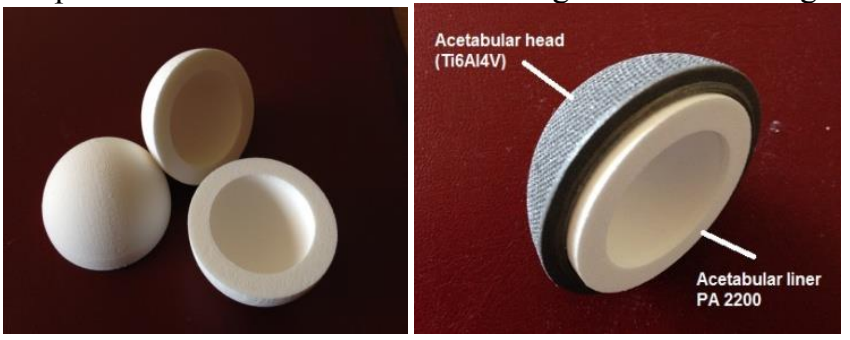

Fig. 6. Acetabular head and acetabular liner made by AM technologies (SLS and SLM).

This research was supported by the OpTi-DeP Project (no. BG101/2016) financed from the UEFISCDI by the Romanian Government and also by the HORIZON 2020 AMaTUC project (GA 691787) financed from EU.

\section{References}

1. F. Bartolomeu, M. Buciumeanu, E. Pinto, N. Alves, F.S. Silva, O. Carvalho, G. Miranda, Transactions of Nonferrous Metals Society of China, 27 (2017)

2. D. I. Băilă, Procedia Engineering, 69 (2014)

3. C. Song, A. Wang, Z. Wu, Z. Chen, Y. Yang, D. Wang, Materials \& Design, 117 (2017)

4. R. E. Huxtable, T. R. Ackland, G. C. Janes, J. R. Ebert, Clinical Biomechanics, 46 (2017)

5. J. Bai, B. Zhang, J. Song, G. Bi, P. Wang, J. Wei, Polymer Testing, 52 (2016)

6. P.-I. Tsai, C.-C. Hsu, S.-Y. Chen, T.-H. Wu, C.-C. Huang, Computers in Biology and Medicine, 76 (2016)

7. Ortho Info, Total hip replacement, http://orthoinfo.aaos.org/topic.cfm?topic=a00377

8. D. Drummer, D. Rietzel, F. Kühnlein, Physics Procedia, 5, Part B (2010)

9. X. Wang, S. Xu, S. Zhou, W.Xu, M. Leary, P. Choong, M. Qian, M. Brandt, Y.M. Xie, Biomaterials, 83 (2016)

10. K. Senthilkumaran, P. M. Pandey, P.V.M. Rao, Materials \& Design, 30, (2009)

11. X. Hua, J. Li, L. Wang, Z. Jin, R. Wilcox, J. Fisher, Journal of Biomechanics, 47 (2014)

12. C.S. Miron Borzan, M.C. Dudescu, V.Ceclan, A. Trif, M. Ridzon, P. Berce, Materiale Plastice, 53 (2016)

13. Waldermark LINK Company of Germany, McMinn Acetabular Reconstruction Cup, https://www.linkorthopaedics.com/en/for-the-physician/products/huefte/primary/cupscementless/mcminn/

14. A. Goldsmith, D. Dowson, G. H. Isaac, J. G. Lancaster, Proceedings of the Institution of Mechanical Engineers, Part H: Journal Engineering in Medicine, 214 (2000) 